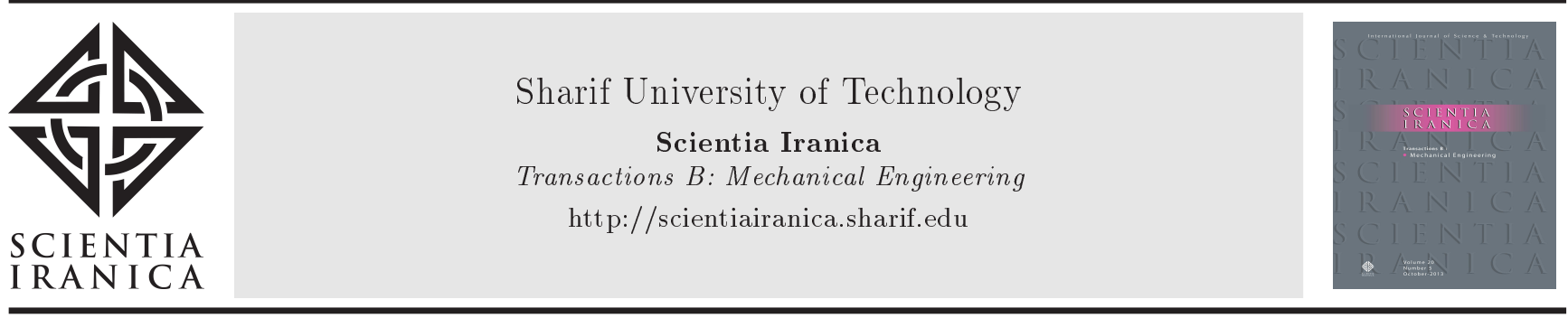

\title{
Prediction of shrinkage ratio of ZA-27 die casting alloy using artificial neural network, computer aided simulation, and comparison with experimental studies
}

\author{
L.C. Kumruoğlu* \\ Faculty of Engineering and Natural Science, Iskenderun Technical University, 31200, Iskenderun, Hatay, Turkey. \\ Received 2 September 2020; received in revised form 27 November 2020; accepted 12 April 2021
}

\author{
KEYWORDS \\ Casting; \\ Simulation; \\ Heat transfer; \\ ANN; \\ Shrinkage; \\ ZA-27.
}

\begin{abstract}
In cast alloys with a long freezing range such as ZA-27, casting defects like porosity and shrinkage may occur in case of failure to control casting variables. In this study, the role of casting variables in the formation of shrinkage and micro-porosity defects in ZA-27 was investigated. The defects of casting were predicted using Artificial Neural Network (ANN) algorithms. To this end, cooling rate, solidification time, temperature, liquid phase, initial mold temperature, and \%shrinkage were obtained from a series of simulation-experimental tests. The heat transfer coefficient of ZA-27 and graphite die was calculated as $2000 \mathrm{~W} /\left(\mathrm{m}^{2} \mathrm{~K}\right)$. In the samples poured into the mold heated at $350^{\circ} \mathrm{C}$, the minimum feeder shrinkage volume was observed. Locations of the chronic hotspot and shrinkage problem were determined and evaluated. It was observed that the casting heated to $150^{\circ} \mathrm{C}$ caused deep shrinkage on the upper and lateral surfaces of the feeder. A good correlation was obtained between the modeling results of the ANN and the experimental results. Optimum ANNs were designed, trained, and tested to predict the shrinkage rate at different initial mold temperatures and in various physical conditions. Thanks to the sigmoid (sigmoaxon) function training, the most systematic modeling ANN set was revealed with $99 \%$ (vol. $7.65 \%$ shrinkage) prediction.
\end{abstract}

(C) 2021 Sharif University of Technology. All rights reserved.

\section{Introduction}

Zinc-Aluminum alloys can act as feasible alternatives to many ferrous and non-ferrous alloys in various engineering applications due to their outstanding advantages such as superior mechanical, physical and tribological properties, corrosion resistance, high damping capacity, castability, environmentally friendliness, and low cost-energy ratio [1-5]. Industry branches employing zinc include automotive parts, transportation [6],

*. Tel.: +905058942801

E-mail address: cenk.kumruoglu@iste.edu.tr

doi: $10.24200 /$ sci.2021.54596.3824 electronic/electrical systems, water taps, sanitary fittings, household goods, fashion products, safety belt blocks, locking mechanisms, wiper motor housings, cylinder locks, some electronic connectors, handles, tap systems, zippers, belt buckles, spring adjuster in bikes, costume jewelry, appliances, etc. have been reported [3]. Recently, more than 25 commercial zinc alloys have been reported for use in the foundry industry. International standards for these alloys are referred to as EN 12844. The commercial and academic names of the mentioned zinc alloys are Zamak 2 (AC43A), Zamak 3 (AC40A), Zamak 5 (AC41A), Zamak 7, ZA8, ZA-12, ZA-27, ACuZinc 5, ACuZinc 10, ALZEN 305, ALZEN 501, and ZEP ${ }^{\circledR}$. Following engineering evaluations of all Zinc-Aluminum alloys, ZA-27 alloy 
has proven the best in terms of mechanical, tribological, and physical properties [1]. The digit " 27 " indicates the nominal weight percentage of aluminum in zinc [7]. ZA-27 alloy can be produced through permanent die casting [8]. However, some of the main problems in casting technology of cast ZA alloys are listed as gassing, oxidation, grain coarsening, uncontrolled cooling rate, heterogeneous microstructure, and microporosity. Nevertheless, the superior mechanical properties are strongly affected by processing parameters, casting temperature, initial mold temperature, cooling rate, liquid phase, and alloying elements [2,3,5,9-12]. In order to obtain reliable mechanical properties, the production parameters must be properly controlled. For example, the effect of processing parameters such as solidification time and initial die temperature in squeeze gravity casting of zinc alloys was studied by Yang [13]. Production by casting is a very complex process and product quality depends on many process parameters. However, the current design of metal foundries is mainly based on "trial and error". The product quality of casting parts and the elimination of possible casting errors are largely determined by the experience of casting designers. It is difficult to optimize the effect of casting parameters with conventional mathematical calculations [14-16]. In order to produce quality casting, the casting parameters should be controlled experimentally or with the aid of engineering and production systems such as ComputerAided Simulation (CAS) $[10,15]$. The defects mentioned above occur in the castings due to wrong choice in selecting the process variables. Aravind et al. employed MAGMASOFT software to simulate the casting process undergoing solidification. Their simulation results demonstrated the possible areas that might be subjected to defects or any other malfunctions [17]. In fact, even computer simulation programs do not provide accurate results in case of sufficient data. This is due to the different physical properties of the foundry where the software is tested and the foundry materials are used in the foundry where the software is used. For example, in the case of ZA-27 casting into the graphite mold examined in this article paper, in the graphite mold casting, although the thermal conductivity coefficient of graphite at room temperature was incorporated into the simulation programs, there is still a limited scope of proper data on the thermal conductivity coefficient of the mold in case of preheating the mold to $150^{\circ} \mathrm{C}$ degrees or higher. Similarly, there is a limited scope of data on how to change the conductivity coefficient values and cooling rate of the solutions to prevent liquid metal from sticking to the surface of the graphite mold. However, casting defects can be reduced by calibrating the data obtained from casting simulation software with real experimental castings and Artificial Neural Networks (ANNs) approach. On the other hand, a more realistic estimation of casting errors can be made using ANN and based on foundry conditions, humidity in the air, ambient temperature, residence time in the furnace, the effect of nucleating, degassing processes, mold temperatures, and changes in these mold temperatures due to the lack of data not introduced to computer simulation software. One of the most critical of these casting defects is the extent of porosity in the casting. In the casting process, shrinkage forms due to the rejection of gas from the liquid metal during solidification and/or failure of the liquid to be fed through the interdendritic regions. Such porosity may occur in the form of micro or macro shrinkage. The macro shrinkage can be compensated by a feeder and a good runner design, while the micro shrinkage is often difficult to predict. Micro shrinkage occurs inside of the cast part, while macro shrinkage occurs mostly out of the parts.

The objective of the present work is to design CAS and ANN models so as to predict micro-porosity and shrinkage problems of ZA-27 alloys as functions of processing parameter and initial mold temperature using ANN sigmoidaxon and ANN tanhaxon transfer functions. The results of this research and those not in the literature are given in the following.

CASs are widely used for predicting and preventing casting defects. However, no CAS studies have been found to predict micro-porosity, surface sink, and shrinkage formation of the ZA-27 alloy. In addition, the micro-porosity and shrinkage formations measured by CAS have been compared with experimental studies. The examination of experimentally produced samples has been carried out with both Radiographic Inspection (RT) and physical techniques. By using graphite die, industrial-scale ZA-27 castings were made without adhesion, and temperatures in the mold were calculated simultaneously. Finally, in addition to experimental and computer-assisted casting and solidification simulation, specific ANN modeling was performed to estimate micro-porosity and shrinkage. This research paper considers the application of CAS and ANN to predicting shrinkage and making a correlation of initial mold temperature, pouring time, temperature, liquid phase, and cooling rate with the shrinkage percentage in ZA-27 casting alloys.

\section{Materials and methods}

\subsection{Materials and experimental studies}

The alloy ZA-27 was chosen as the casting material due to its popular use in many industries, high strength, low production cost, and low pouring temperature $[2,18]$. The chemical composition of ZA-27 alloy is given in Table 1.

All data, casting processing, and material properties were calculated by the computer programs and 
Table 1. The chemical composition of ZA-27 alloy (wt.\%).

\begin{tabular}{lccccccc}
\hline Chemical & $\mathbf{Z n}$ & $\mathbf{A l}$ & $\mathbf{M g}$ & $\mathbf{C u}$ & $\mathbf{F e}$ & $\mathbf{P b}$ & $\mathbf{C d}$ \\
\hline Composition\% & 72.6 & 25.00 & 0.01 & 2.26 & 0.07 & 0.01 & 0.01 \\
\hline
\end{tabular}

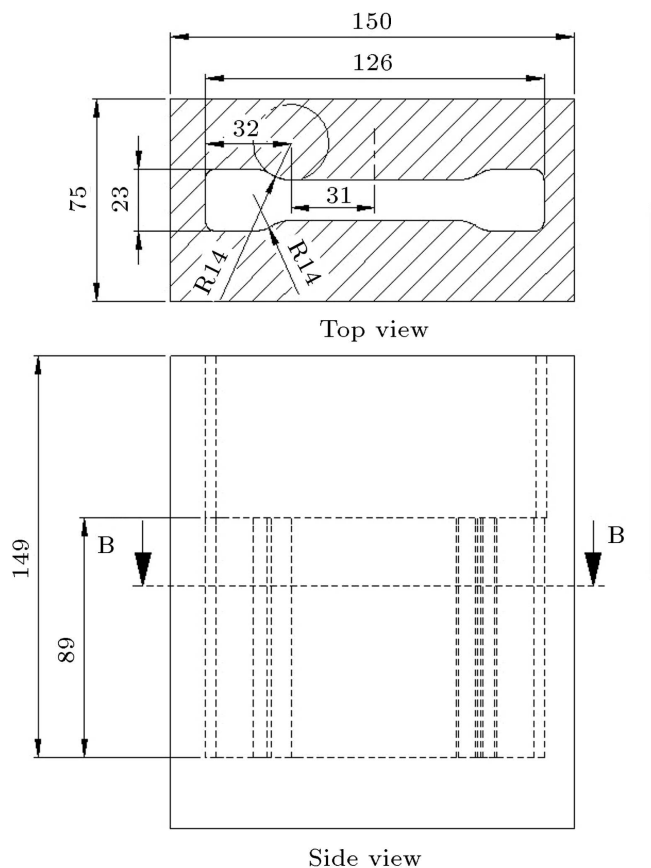

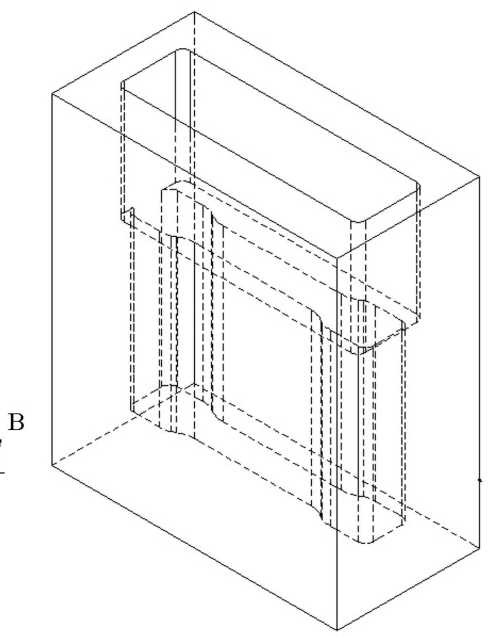

Isometric view

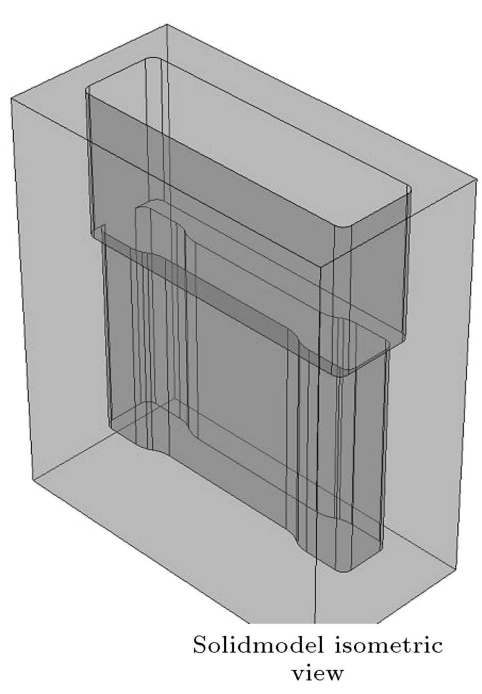

Figure 1. The technical drawing of the high-density graphite permanent mold (dimensions are in $\mathrm{mm}$ ).

Table 2. The thermal and physical properties of ZA-27.

\begin{tabular}{cccc}
\hline $\begin{array}{c}\text { Temperature } \\
\left({ }^{\circ} \mathbf{C}\right)\end{array}$ & $\begin{array}{c}\text { Density } \\
\left(\mathbf{k g} / \mathbf{m}^{\mathbf{3}}\right)\end{array}$ & $\begin{array}{c}\text { Specific } \\
\text { heat } \\
\left(\mathbf{J} / \mathbf{k g} /{ }^{\circ} \mathbf{C}\right)\end{array}$ & $\begin{array}{c}\text { Heat } \\
\text { conduction } \\
\left(\mathbf{W} / \mathbf{m} /{ }^{\circ} \mathbf{C}\right)\end{array}$ \\
\hline 20 & 5930 & 525 & 122,500 \\
350 & 5780 & - & - \\
620 & 5370 & - & - \\
800 & 5300 & - & - \\
\hline
\end{tabular}

engineering database. The physical and thermal properties of casting material are shown in Table 2.

The casting temperatures of $550^{\circ} \mathrm{C}, 600^{\circ} \mathrm{C}$, and $650^{\circ} \mathrm{C}$ were chosen for each different mold with a preheating temperature. The high casting temperature increases fluidity and reduces the cooling rate at the metal/graphite mold interface. Since ZA-27 has a wide solidification range, the casting temperature is preferred to be $650^{\circ} \mathrm{C}$ so that the fluidity required to fill the mold can be provided. The reason why the casting temperature is preferred at $550^{\circ} \mathrm{C}$ is to obtain a low-cost product and a fine-grained microstructure in metallurgical terms. This condition causes microstructural changes such as grain size and affects the mold life. Also, in ANN models, casting temperature of $550^{\circ} \mathrm{C}$ min and maximum casting temperature of $650^{\circ} \mathrm{C}$, which are assumed as input values, directly affect the estimated shrinkage percentage in the output layer. The graphite mold is designed in the form of a rectangular shape to measure temperature distribution during the mold filling and solidification. The technical drawing and a photograph of the high-density graphite permanent mold are shown in Figure 1. To measure the temperature and record the cooling data during the solidification process, 3 holes were drilled through the mold walls and $3 \mathrm{~K}$-type (Ni-Cr) quartz-insulated tube thermocouples were placed in these holes. Thermocouples can feasibly monitor the temperature of the mold, cavity surface, and heat transfer medium (e.g., the coolant) [12]. Quartz-insulated tube thermocouples prevented the contact of $\mathrm{NiCr}$ thermocouple wires with liquid metal during casting, impeded short circuit formation, and facilitated obtaining continuous temperature data. As shown in Figures 2 and 3, different thermocouples were placed from top to bottom with the numbers 3, 2, and 1. During casting, the holes were sealed with a paste made of a mixture of zircon sand and sodium silicate to prevent liquid metal from flowing out of the mold through the mold edge and thermocouple holes. This paste is practically gluing two half molds and exhibits refractory properties, even 

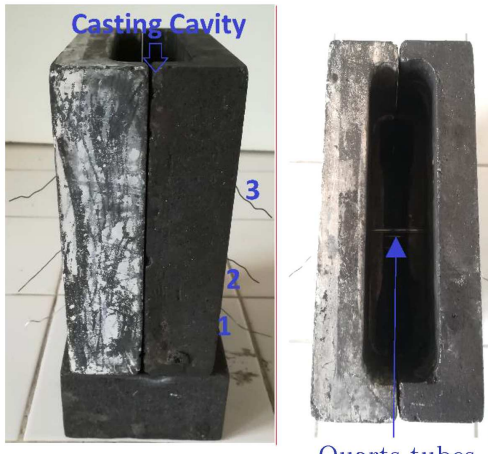

Quarts tubes

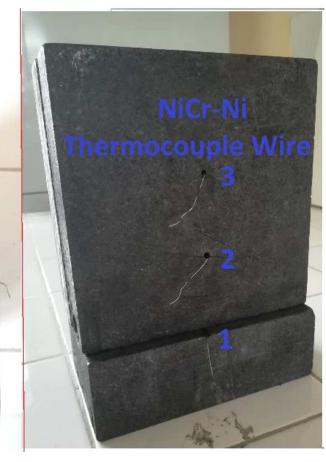

Figure 2. The high-density graphite permanent mold and quartz-insulated tube for thermocouples setup.

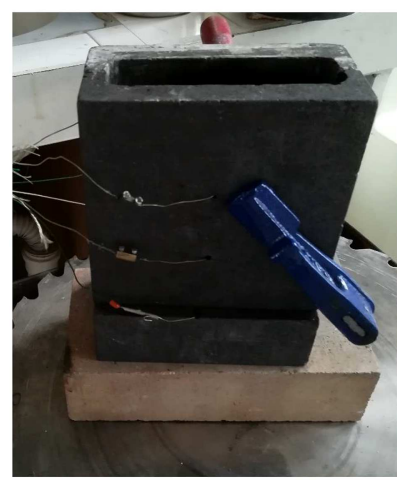

(a)

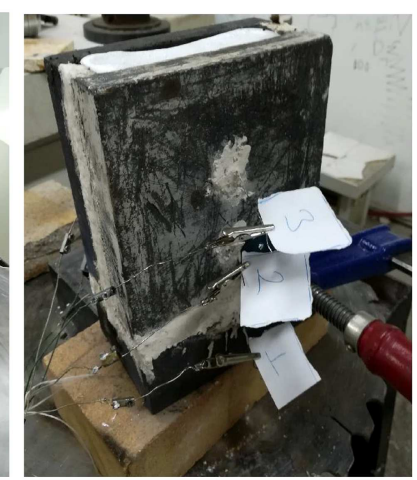

(b)
Figure 3. Thermocouples' locations in the mold: (a) before casting and (b) after casting.

at high temperatures. Thermocouples placed on the mold before casting and mold photos after casting are given in Figure 3. In order to achieve the required heat transfer and minimum distortion, the mold thickness was determined as $75 \mathrm{~mm}$. Graphite has high thermal conductivity and is suitable for machining; therefore, it was chosen as a molding material. Silicon Carbide (SiC) heating elements are mounted on all exterior surfaces of the graphite mold at certain intervals. In this way, the mold preheating was carried out in a controlled manner.

Casting research was performed 4 times by changing initial mold temperature as $150^{\circ} \mathrm{C}, 250^{\circ} \mathrm{C}, 300^{\circ} \mathrm{C}$, and $350^{\circ} \mathrm{C}$. Here, it would be useful to explain why mold preheat temperatures are preferred between $150^{\circ} \mathrm{C}$ and $350^{\circ} \mathrm{C}$. Temperatures below $150^{\circ} \mathrm{C}$ transform the microstructure into a finer-grained form by making a chill effect with rapid solidification. It is known that metals with a fine-grained microstructure have better mechanical properties. However, increasing the mechanical properties in this way is subject to high costs as a disadvantage. Production carried out under industrial conditions is focused on quality and product quantity. In these conditions, product (casting)/hour rates are very important. In a foundry producing a ZA-
27 alloy valve, the mold (metal) temperature increases after each casting. The heat of the liquid metal is transferred to the mold through conduction. If the initial mold temperature begins with a temperature like $100^{\circ} \mathrm{C}$, it will gradually increase to $500^{\circ} \mathrm{C}$, which is the melting temperature "after 10 castings for example". In this case, it is necessary to constantly cool the heated mold with a liquid, air, or gas, causing cost, complexity, and environmental risks. In this case, factories use more than one metal mold and in case the heated molds are cooled, they are cast. Cold molds are exposed to the risk of liquid metal splashes. Another problem that deserves attention is the risk of condensation of water vapor remaining in the cold molds. Casting in a mold containing moisture can be life-threatening due to vapor expansion. The mold life cycle is reduced if the mold temperature is low. In addition, at low mold temperatures, the viscosity of the metal decreases and the mold-filling problem arises. Therefore, the lowest mold preheating temperature is preferred to be $150^{\circ} \mathrm{C}$. On the other hand, high mold temperatures decrease the number of productions per casting at a given time in metal casting and prolong the mold opening time. Furthermore, the high mold temperature technically carries the risk of adhesion between the liquid metal and graphite-die and causes graphite-die to deform and erode rapidly. At the same time, hot molds $\left(400-450^{\circ} \mathrm{C}\right)$ reduce the mechanical properties of the solidified metal. Because the cooling rate is slow in hot molds, a coarse-grained microstructure forms. Moreover, the risk of shrinkage and porosity is much higher in hot molds. Therefore, it is not preferred industrially. For these reasons, the preheating mold temperature range was chosen between $150-350^{\circ} \mathrm{C}$.

For each casting, the liquid metal was fully poured in the mold at $550^{\circ} \mathrm{C}, 600^{\circ} \mathrm{C}$, and $650^{\circ} \mathrm{C}$, respectively, and solidification data were logged. After the solidification, all data including initial mold temperature, solidification duration, temperature-time gradient, cooling rate, liquid phase, and shrinkage data were obtained and exported so as to use an Excel table. Different initial mold temperatures of the ZA-27 cast products taken after casting are given in Figure 4.

\subsection{Modelling with casting simulation}

From the experimental castings, 100 temperature measurement data sets were collected from three different regions with Picolog Data Logger. Each temperature data set was transferred to the simulation program and 6 different Heat Transfer Coefficient (HTC) values were used to simulate experimental cooling curves and simulation cooling curves. These studies were performed separately for each preheat temperature to match the experimental data with the simulation data. Thus, the HTC of the preheated graphite was determined exactly. As a matter of fact, in many 


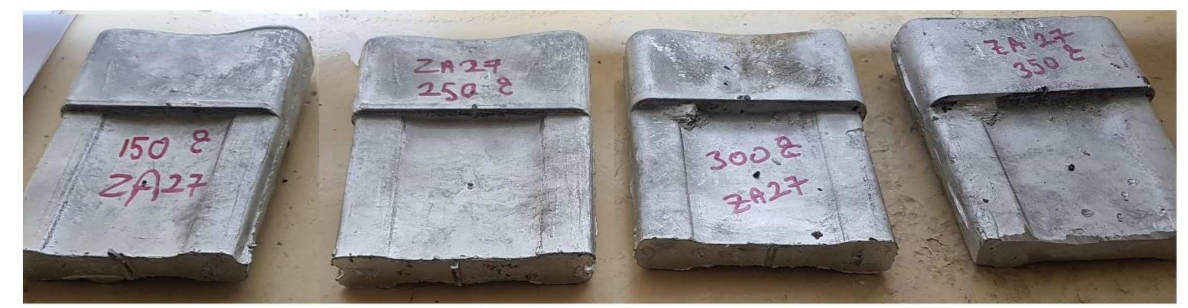

Figure 4. ZA-27 alloys produced by casting poured into the mold at 4 different temperatures.

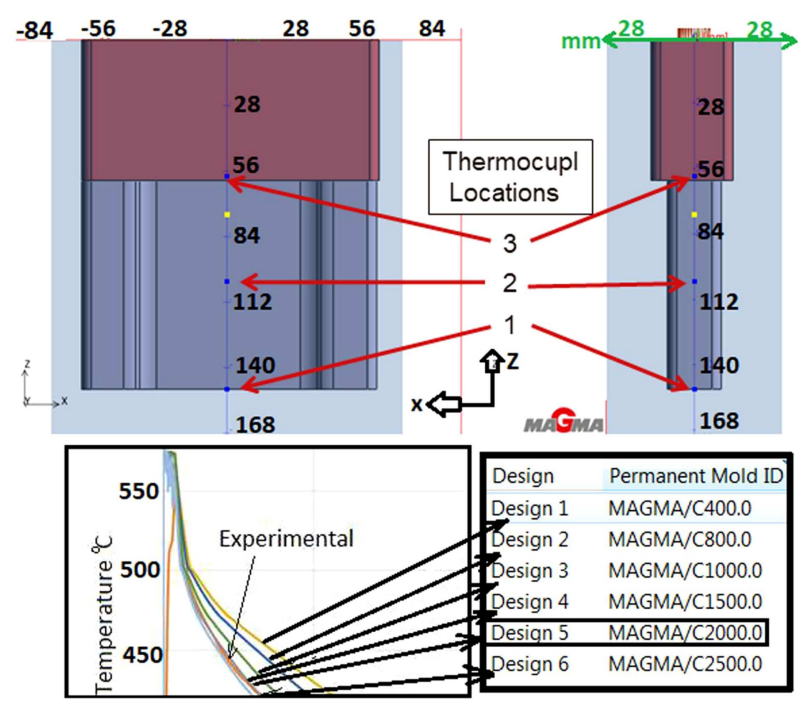

Figure 5. Heat Transfer Coefficient (HTC) determined by simulation and experimental calculation.

simulation software products, the data recorded in the database is presented only as room temperature HTC by default. In the simulation studies, primarily, the HTC between the mold and ZA-27 casting was determined. These studies are given in Figure 5. The most important point here is that the values measured from all the three thermocouples are the same as those in simulation. Six different designs were made so that simulation and experimental data could be the same and as a result, it was observed that design 5 was similar to the experimental casting.

After determining the correct HTC, filling and solidification simulations were done at different mold preheating temperatures. Micro-porosity and shrinkage analyses were carried out for the ZA-27 alloy poured at each mold temperature using the verified and calibrated HTC and cooling curves.

\subsection{Radiography and metallographic examination}

The amount and location of the porosity formed in the experimentally produced ZA-27 alloys were determined by radiography and metallographic examination from sections. RI or short wavelength electromagnetic radiation was applied to the material to find internal structure defects such as industrial X-ray, casting cavity, and inclusion. X-ray and a radioactive source (IR-192, Co-60 or, in rare cases, Cs-137) were used in the experiments in the RT system. The parameters used in RT investigations are optimized for ZA-27 alloy and determined as X-ray: current $=5(\mathrm{~mA})$; voltage $=165(\mathrm{kV})$; and exposure time $=120 \mathrm{~s}$. In the metallographic examination, the routine method was examined and the hardness values for the samples were also measured. In this way, a general opinion about the mechanical properties was obtained.

\subsection{Modeling with an ANN}

Abiodun et al. reported the details of feedforward and feedback propagation ANN models for research focus based on data analysis factors like accuracy, processing speed, latency, fault tolerance, volume, scalability, convergence, and performance [19]. In addition, the hybrid GA-PSO framework modeling in data mining has been investigated and researched [20]. According to literature researches, it is understood that ANN model is frequently used in different disciplines by processing non-linear data among many artificial learning rules, and the results could act as a more common alternative to those of methods such as fuzzy control [21]. In the article published by Sharma, activation functions in neural networks sigmoid, tanh, softmax, ReLU, and leaky ReLU were explained. It is understood that sigmoid, tanh transfer functions explained by Sharma [22] and Cavaleri [23] will ideally predict the geometric form of the cooling curve that occurs due to die temperature, Critical Liquid Fraction (CLF), and metallurgical ZA-27 alloy phase transformations after metal casting. ANN modeling, with a wide range of applications, was used to predict casting defects of ZA-27 alloy. Casting parameters and amount of shrinkage determined by experimental and casting simulations were applied to artificial intelligence and learning modules, and the amount of shrinkage was estimated. ANN modeling is defined as a nonlinear statistical analysis technique [24]. ANN is becoming more and more important research area due to the ability of ANN applications to test experimentally obtained topologies and experimental parameters using computer bandwidth. An ANN is a mathematical model that consists of several large layers of highly interconnected processing elements organized into units 
called neurons, the geometry and functionality of which have been likened to those of the human brain $[2,18,25]$. Compared to most of the soft computing techniques, ANNs work optimally if the relationship between the inputs and outputs is highly non-linear. ANNs are favorably acceptable for solving problems and no algorithms or a specific set of rules should be adopted to resolve the problem [26]. In particular, such substitute models can be established through a training process with limited available data which can be used to predict pre-selected parameters, thus reducing the need for time- and cost-consuming experiments [23]. Moghaddam and Kolahan modeled and optimized Electrical Discharge Machining (EDM) process using ANN and Particle Swarm Optimization (PSO) algorithm by establishing a neural network with back propagation algorithm (BPNN). Their results demonstrated that the proposed modeling method (BPNN) accurately simulated the real EDM process with less than $1 \%$ error and the PSO optimization algorithm with less than $4 \%$ error. However, because the ZA-27 alloy has a wide solidification range and the continuous phase transformations occur during solidification depending on the temperature, error greater than $4 \%$ was obtained in the PSO model [27]. Therefore, the PSO model was not preferred for the percentage shrinkage estimation affected by the die preheat temperature and phase transformation. Feed-Forward Neural Network (FFNN) is the most commonly used ANNs architecture. It consists of a layer of input, a layer of output, and one or more hidden layers of neurons for full interconnection between input and output layers. According to the electrical potential change of the creep test of composites, the ANN-FFNN model was studied by Altabey et al. [28] Some of the models in our current study were similar to those of Altabey et al. [28]. The basic network structure of the multilayer feedforward ANN for shrinkage estimation is shown in Figure 6 . This structure consists of an ANN, an input layer, two hidden layers, and an output layer.

Five data sets were used as inputs: initial mold temperature, pouring time, casting temperature, cooling rate, and \% critical liquid phase. Two hidden layers of the performed models consist of 14 and 7 neurons (node or processing element), respectively. Finally, $\%$ shrinkage and \%porosity were set as output (desired) parameters. Using a small number of neurons in hidden layers will cause underfitting. Underfitting occurs when there are a small number of neurons to adequately specify signals in a complex data set. On the other hand, using too many neurons in the hidden layers can result in different problems such as overfitting. Overfitting

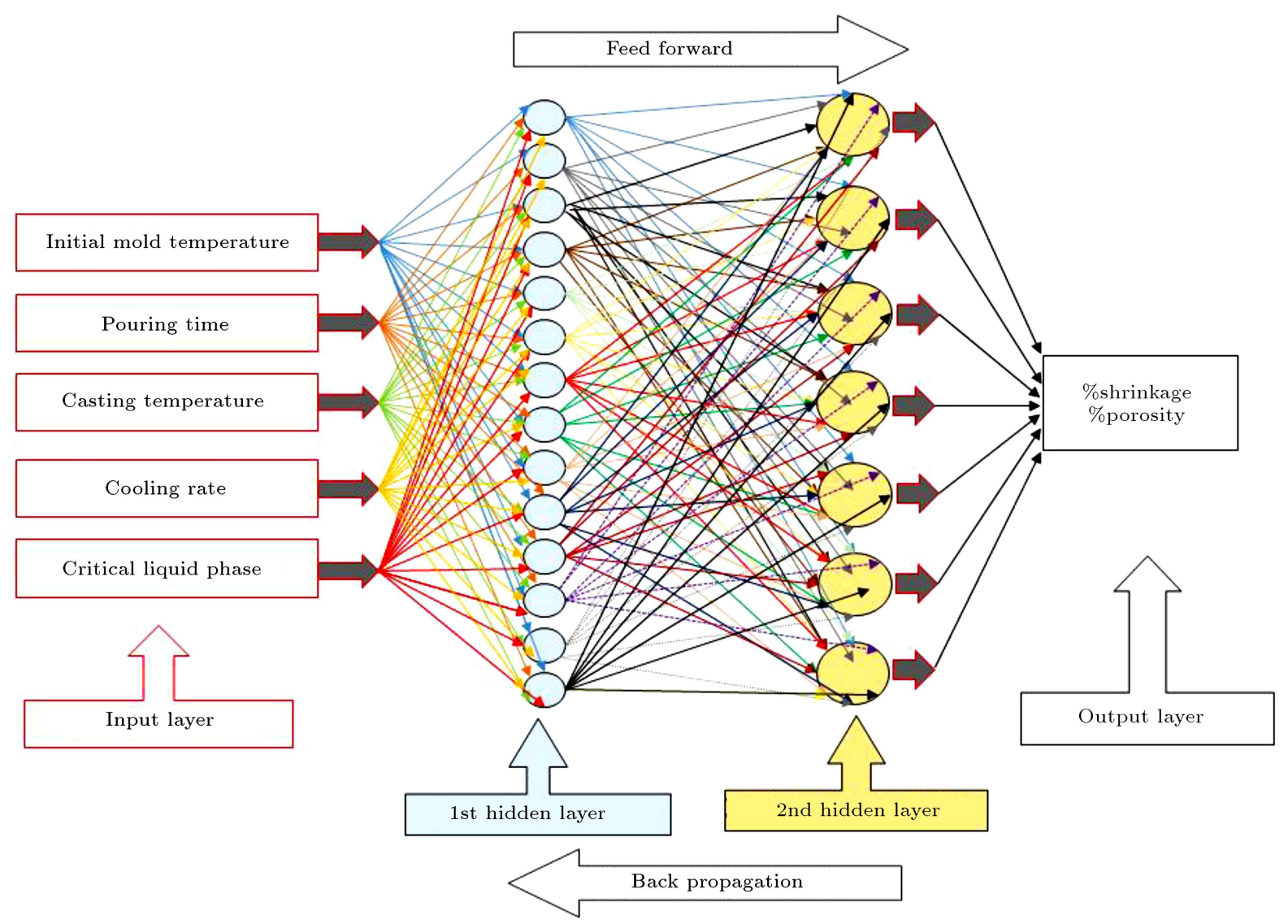

Figure 6. The structure of the Artificial Neural Network (ANN) used in modeling the ZA-27 casting and solidification. 
occurs when the neural network must process a lot of information, while the training set does not have enough information to train all neurons. From time to time, another problem can arise even if the training data are sufficient. Excessive numbers of neurons in hidden layers can increase the time required to train the network or even make it impossible to train the neural network adequately. Evidently, some alignment must be done between too many and too few neurons in hidden layers. Various combinations of neurons have been also studied to obtain optimum results from the model. These studies are generally carried out through trial and error. Tangent transfer function is used in the model. Details of input variables can be seen below. Hashim et al. [29] evaluated the welding properties and weld defects using ANN models. In his paper, ANN algorithms such as Multilayer Perceptron, AdaptiveNetwork-Based Fuzzy Inference System, Feedforward Backpropagation, and Self-Organizing Map were evaluated to detect weld defects. It was stated that the defects in the welding process would mostly be related to solidification, shrinkage, and CLF [30,31]. For this reason, the methods suggested by Hashim were preferred for shrinkage modeling of ZA-27 alloy using ANN given that the Feedforward Backpropagation algorithm has a quick and high percentage of accuracy that can be obtained. Hashim stated that $95 \%$ accuracy was achieved via Feedforward Backpropagation algorithm [29]. For all tests of the current ZA-27 alloy, 2646 data sets were obtained. All values used in sigmoid function were normalized between 0 and 1 by using linear scaling; at the same time, all values were normalized between -1 and 1 for tangent function. The sigmoid function was used in the activation function of the neural network. The most important reason behind choosing the sigmoid function is that its value lies between $(0$ and 1$)$. It is particularly preferred in models by which we need to estimate the probability as an output. Randomly selected 1901 data sets were used for training the network, 303 data sets for testing, and 440 data sets for production. Then, the ANN simulation and modeling approaches were applied. The network was arranged as five input parameters and one output parameter. Hence, the architecture of ANN becomes $5-14-7-1: 5$ corresponding to the input values; 14 to the number of hidden layers with 1 neurons; 7 to the number of hidden layers with 2 neurons; and 1 to the outputs. Also, genetic algorithms operating on networks model were used for training data. The modular neural network was employed for the systems. Modular neural networks represent a special class of multilayer perceptron. The feedbacks of error were given using Back Propagation Algorithms (BPAs). For the model training, two different functions were utilized: sigmoid (sigmoaxon) and tangent (tanhaxon). Momentum learning rule and on-line weight update were employed for each function. Optimal ANNs were once designed, trained, tested, and used to predict shrinkage ratio for various sets of initial mold temperature and physical conditions.

The most important parameter of the proper functioning of a neural network model is to train the network system. In this proposed network system, to conduct porosity estimation, training was conducted using BPA. BPA is the gradient descent method used to minimize the square error function and the most commonly used formula in ANN is given below [32]:

$$
E=1 / 2 \sum_{j=1}^{p}\left\|y^{(i)}-d^{(i)}\right\|^{2}
$$

The subscripts " $i$ ", "ith" given in this formula refer to the input patterns. The symbols " $y$ " and " $d$ " are the calculated outputs and the desired outputs of the model, respectively. The learning procedure in the BPA consists of 10 mathematical operations and is listed as follows. In the first operation, weights and threshold values are initialized; all weights and threshold are set to small random values. In the second operation, continuous value input vectors, $X_{1}, X_{2}, \cdots, X_{n}$, and the desired outputs, $\theta_{1}, \theta_{2}, \cdots \theta_{n}, \cdots$, are explicitly given. Usually, training sets are normalized to values between -0.9 and 0.9 during training. In the operation, used in Eq. (3), the outputs of each node in the hidden layer are calculated, as shown in Eq. (2).

$$
h_{j}=f\left(\sum_{j=1}^{n} W_{i j} X_{i}-\theta_{k}\right),
$$

where $W_{i j}$ is the weight between the input and hidden layers, $\theta_{k}$ is the bias between the input and hidden layers, and $f$ is the activation function. Activation functions are used for nonlinear transformations in multi-layer ANNs. The output of hidden layers is normalized by some activation functions to obtain backward derivatives in hidden layers (the difference in learning is taken together with backward derivatives). Some of these activation functions include sigmoid, tanch, ReLu, PreLu, and so on. In the next operation, the output of each node in the output layer is calculated through the following formula:

$$
Q_{k j}=f\left(\sum_{J=1}^{n} W_{k j} X_{k i}-\theta_{k}\right) .
$$

The symbol $Q$ in Eq. (3) is the vector of the output layer nodes, $W_{k j}$ is the weights of the hidden and output layers, and $\theta_{k}$ is the bias between the hidden and output layers.

$$
\begin{aligned}
& f(x)=\frac{1-e^{-a x}}{1+e^{-a x}}, \\
& \delta k=\Theta k(1-\Theta k)(Y-\Theta k) .
\end{aligned}
$$


$\Theta k$ is the target of the output layer and $\delta k$ represents the error vectors of each output node. Then, the hidden layer error is calculated.

$$
\delta_{j}=h_{j}\left(1-h_{j}\right) \sum_{k=1}^{m} \delta_{k} \omega_{k j},
$$

where $\delta_{k}$ is the error vector for each hidden layer.

In the operation shown in Eq. (6), the output layer error between the target and observed outputs is calculated. This operation (Eq. (6)) is the same as that in Eq. (5). In the next step, hidden layer error is calculated using Eq. (6). Then, using Eq. (7), the weights and thresholds for the output layer should be adjusted.

$$
\omega_{k j}=(t+1)=\omega_{k j}(t)+{ }^{*} \delta k h j+\eta\left(\omega_{k j}(t)-\omega_{k j}(t-1)\right),
$$

$$
\theta k(t+1)=\theta k(t)+{ }^{*} \delta k .
$$

The symbol * is the learning rate known as the convergence ratio between the current solution and the global minimum. The gradient is a vector-valued function and as a vector, it has both direction and magnitude. The gradient descent algorithm multiplies the gradient by a number, e.g., learning rate or step size, to determine the next point. This formula also uses the momentum value that helps the network overcome the local minimum level and, then, adjusts the weights and thresholds on the hidden layer.

$$
\begin{gathered}
\omega n=(t+1)=\omega j i(t)+{ }^{*} \delta j h i+\eta(\omega j i(t) \\
-\omega j i(t-1)) \\
\theta j(t+1)=\theta j(t)+{ }^{*} \delta t .
\end{gathered}
$$

Finally, for each layer and each neuron, the output layer error is repeated using operations in Eqs. (2) and (9) in each pair of patterns until the error is within the specified tolerance [32].

The data derived from the casting process used in this ANN modeling were collected from our foundry laboratory. The reason for this is to control the experimental parameters much more precisely. While planning the scenario of this article, the items listed below were primarily determined in a systematic manner:

Question 1. In the field of metallurgy, which area in the industrial process parameters and production is the most difficult to control?

Question 2. What is the metallurgy field with the largest control and number of variables?

Question 3. What are the materials that are commercially needed in many engineering fields?
Question 4. What are the metals that do not have sufficient technical documents and articles about their production?

Question 5. How should complex process parameters be controlled in an economical and practical way?

The questions mentioned above have been thoroughly discussed. As a result, such issues as welding, heat treatment, plating, coating, forging, rolling, extrusion, powder metallurgy, casting, etc. were evaluated and consultations were made with industry representatives and engineers. The casting process which includes many technical issues such as melting, smelting, casting calculations, molding, phase transformations, volume changes, solidification, heat transfer, and material selection was chosen according to the received feedback. Materials that are commercially needed in many engineering fields are known as steel, cast iron, aluminum, copper, and zinc. Zinc is the fourth metal in the world after iron, aluminum, and copper and is the most prominent of all these metals. In an up-to-date review article published by Pola et al., the importance of zinc was explained in detail with technical data [3]. On the other hand, when a detailed literature search is made on zinc alloys, it is understood that a much more limited research is done compared to other common metals such as steel and aluminum. Moreover, studies have been made on the use of zinc alloys as biomaterials due to their biodegradable and load-bearing properties [33]. The ZA-27 alloy is a zinc-aluminum alloy in the $\mathrm{Zn}-\mathrm{Al}$ alloy group, with an aluminum content of wt.27\% Al, high strength (400 $\mathrm{MPa})$, high melting temperature, and lowest density. Zinc alloys are usually produced by cold chamber die-cast casting methods due to their low melting temperatures. In this way, mass production can be made. However, the weight and dimensions of the parts produced by cold chamber die-cast machines are limited. Numerically, although the weight of a work piece produced by a die casting machine is unlimited, these weights are extremely narrow from an engineering point of view. For example, when the catalog data of a company that produces die-cast machines commercially are examined, the weight limits of the cast part are $1 / 14 \mathrm{oz}(2 \mathrm{~g})$ to $3 / 4 \mathrm{lb}(337 \mathrm{~g})$. On the basis of size, it is in the form of minuscule to $4^{\prime \prime} \times 4^{\prime \prime} \times 1^{\prime \prime}$ [34]. In this case, it is very difficult and even unreasonable in engineering terms to produce ZA alloys weighing 400 grams or more with any pressure die-cast casting machine. On the other hand, the crucial problem of die casting is porosity. If porosity in the product be detrimental to engineering function, it should be clearly defined before die design since it is actually impossible to accomplish zero porosity in die casting. As a result, it is an extremely important problem in which the weight and dimensions of the work piece in 
die casting are limited and that the porosity trapped in the work piece cannot be prevented. In this case, it is necessary to develop alternative casting techniques for the production of work pieces that are both heavier than 500 grams and do not contain porosity. In addition to the problems explained above, this study aims to produce ZA-27 alloy or other alloys by the casting technique without any problem by increasing the mechanical properties. In this study, the process parameters that are of critical importance in terms of metallurgical quality and their effects on casting properties were examined by changing a certain range. The mentioned parameters include the following:

- Liquidus temperature: $500^{\circ} \mathrm{C}$;

- Solidus temperature: $380^{\circ} \mathrm{C}$;

- Casting temperature: $550-650^{\circ} \mathrm{C}$;

- Casting time (pouring duration): 3-12 sec;

- Cooling rate from $10^{\circ} \mathrm{C} / \mathrm{sec}$ to $50^{\circ} \mathrm{C} / \mathrm{sec}$;

- Latent heat: $190 \mathrm{~kJ} / \mathrm{kg}$;

- Latent heat eutectic: $124 \mathrm{~kJ} / \mathrm{kg}$;

- CLF from $40 \%$ to $60 \%$;

- Surface tension coefficient $0.8 \mathrm{~N} / \mathrm{m}$.

The estimated volumetric shrinkage and porosity percentage in the output layer were determined as min $0 \%$ and $\max 10 \%$, respectively. The data collection procedure for this study was carried out via the following explanations. In laboratory conditions, a total of 25 castings were performed through 5 times repetition for each casting. Many temperature measurements from 3 different regions including inside the mold, from the mold interface, outside the mold and inside the melting crucible were performed and recorded for 10 milliseconds. As casting parameters, the porosity and shrinkage ratios of the cast work piece were determined by changing the initial mold temperature in a wide temperature range from $150^{\circ} \mathrm{C}$ to $350^{\circ} \mathrm{C}$. The obtained data were modeled with ANN, the most ideal parameters of which were determined within the framework of the current learning rules and the casting quality at a temperature without casting experiment was evaluated within the scope of porosity and shrinkage output.

Using experimental castings, simulation studies, and ANN modeling, a synergistic study was performed at initial mold temperatures of $150^{\circ} \mathrm{C}, 200^{\circ} \mathrm{C}, 250^{\circ} \mathrm{C}$, $300^{\circ} \mathrm{C}$, and $350^{\circ} \mathrm{C}$ degrees and the amount of shrinkage was calculated for each temperature. With this triple verification, experimental results, simulation data, and ANN models at initial mold temperatures of $150^{\circ} \mathrm{C}$, $250^{\circ} \mathrm{C}, 300^{\circ} \mathrm{C}$, and $350^{\circ} \mathrm{C}$ were considered and the amount of shrinkage at the initial mold temperature of $200^{\circ} \mathrm{C}$ was estimated as learning output data.

\section{Results and discussions}

Hot spot is defined as the hottest location of the metal that solidifies in the mold, and it is the location that cools down later than other locations because the heat cannot be transferred adequately. Feeding efficiency and shrinkage are two of the most important parameters in the solidification process that take place after casting and a function of these two parameters are location and temperature of the isolated hot spots. It is essential that the location and temperature of the isolated hot spots be determined $[35,36]$. For this reason, hotspot locations are determined primarily. The simulation report showing the hot spot locations is given in Figure 7 . The temperatures given in the images in Figure 7 are the initial temperatures of the molds.

As a result of the hotspot simulation performed at each initial mold heating temperature, it was understood that the hotspot locations were inside the feeder and the hotspot formed a larger volume with the increasing mold temperature. It is understood that the hotspot volume and the initial mold heating temperature are proportional, which is because of the slower cooling of the mold heated to $350^{\circ} \mathrm{C}$. The hotspot indicates that adjacent areas in the casting can be effectively fed and the hotspot must be inside the feeder to ensure perfect casting [37].

Another computer simulation study has been run to assess the porosity and shrinkage percentage and distributions in the mold (Figure 8). Shrinkage (surface depression or sink) is a casting defect caused by metal density variation during solidification and it usually occurs on the upper surface of the casting work piece [38]. During solidification, the density increases and the liquid metal volume decreases as a function of solidification and phase transformation. Afterward, the liquid metal shrinks and micro-macro porosities and shrinkages occur in/on the solidified metal. The formation of shrinkage in liquid metal continues up until solidus temperature. Shrinkage can be prevented by the feeder added to the upper surface of the casting according to the modulus criteria. The section view of $3 \mathrm{D} \%$ shrinkage in the casting part evaluated by simulation is given in Figure 8. According to Figure 8, it is observed that the percentage and geometry of shrinkage vary depending on the cooling rate. The shrinkage shown in Figure $8\left(150^{\circ} \mathrm{C}\right)$ is narrow on the top of the cast part on the $Y$ and $X$ axes. The shrinkage observed at the top of the feeder at a mold temperature of $150^{\circ} \mathrm{C}$ is in the form of an ellipse, and as the mold temperature increases, it turns into a rectangular form with a small radius at the corners.

It can be realized that the shrinkage type in zinc alloys can be affected by an initial mold temperature in gravity die casting. Due to the gravity effect of the liq- 

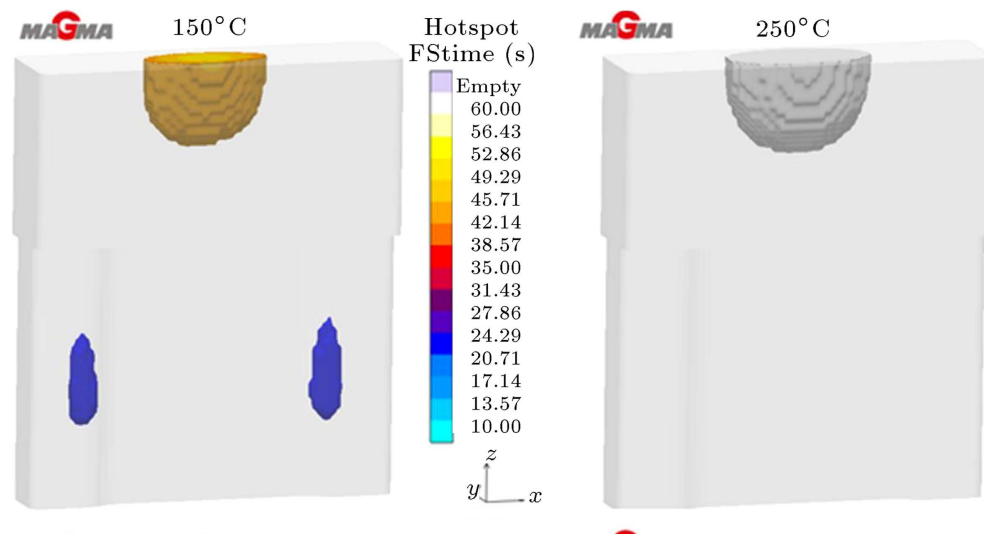

Hotspot FStime (s)
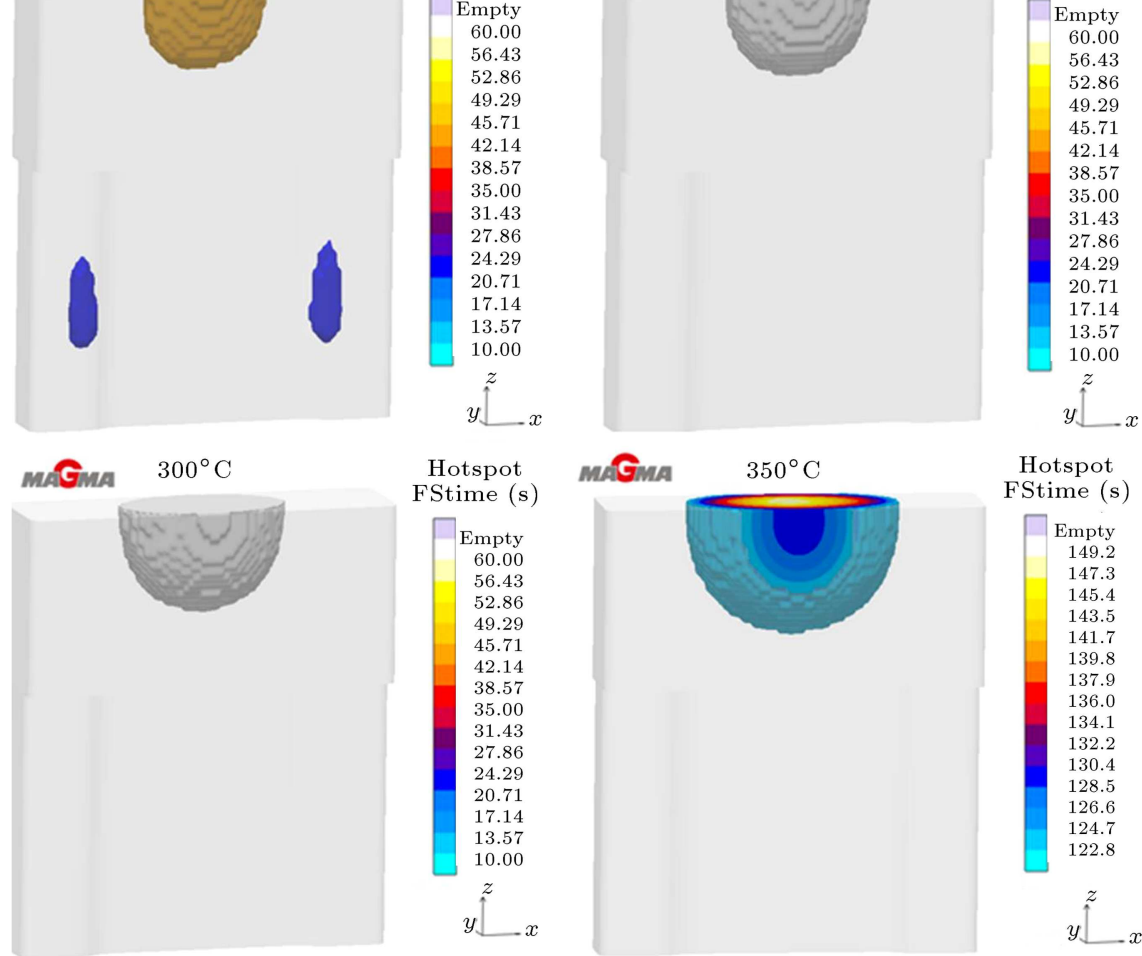

Hotspot FStime (s)

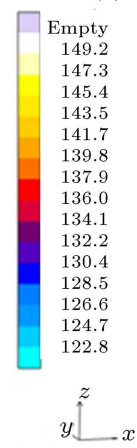

Figure 7. Hotspot FS time locations.

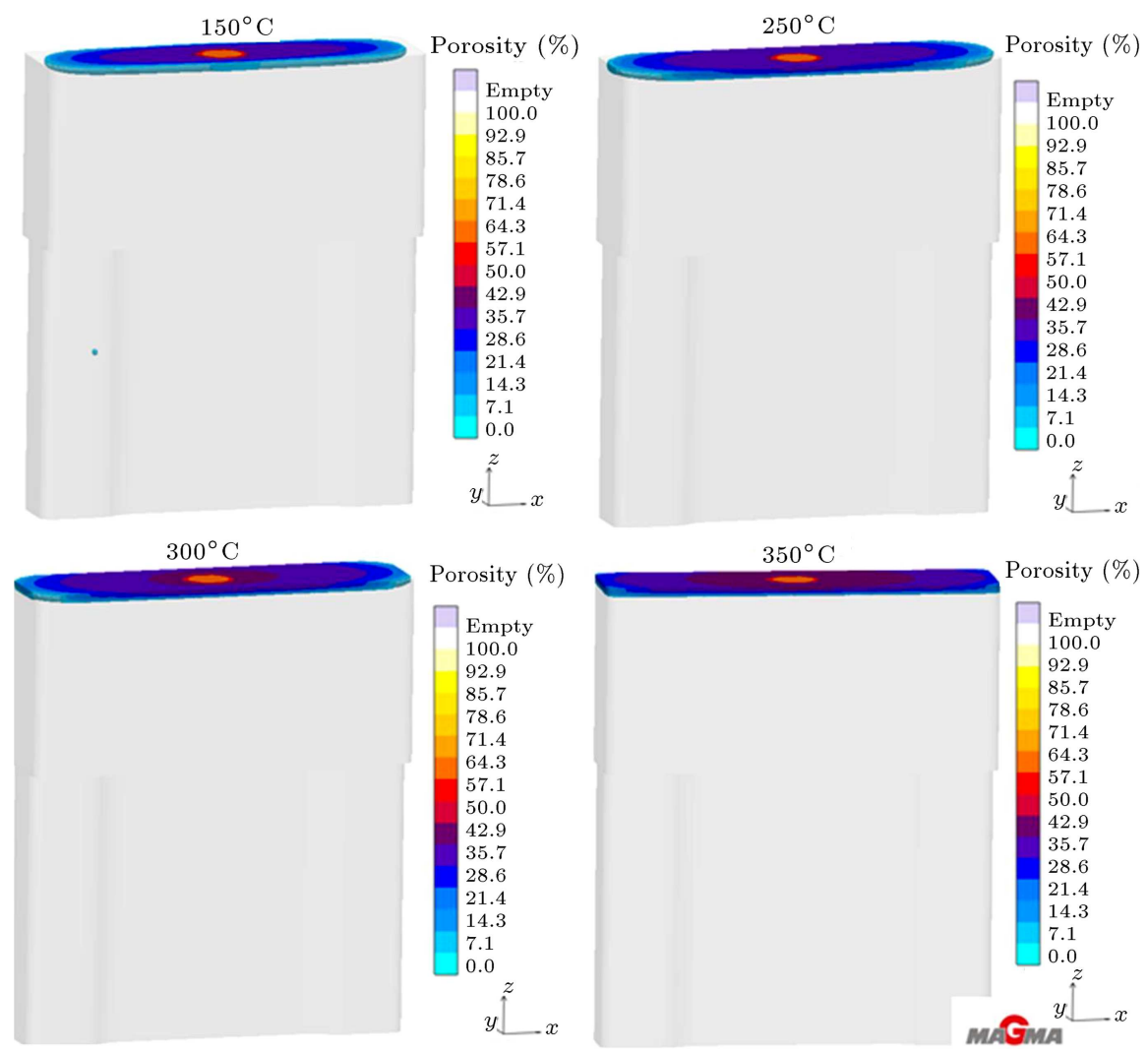

Figure 8. \% surface porosity forming on the upper surfaces of feeder after casting at different mold preheating temperatures. 

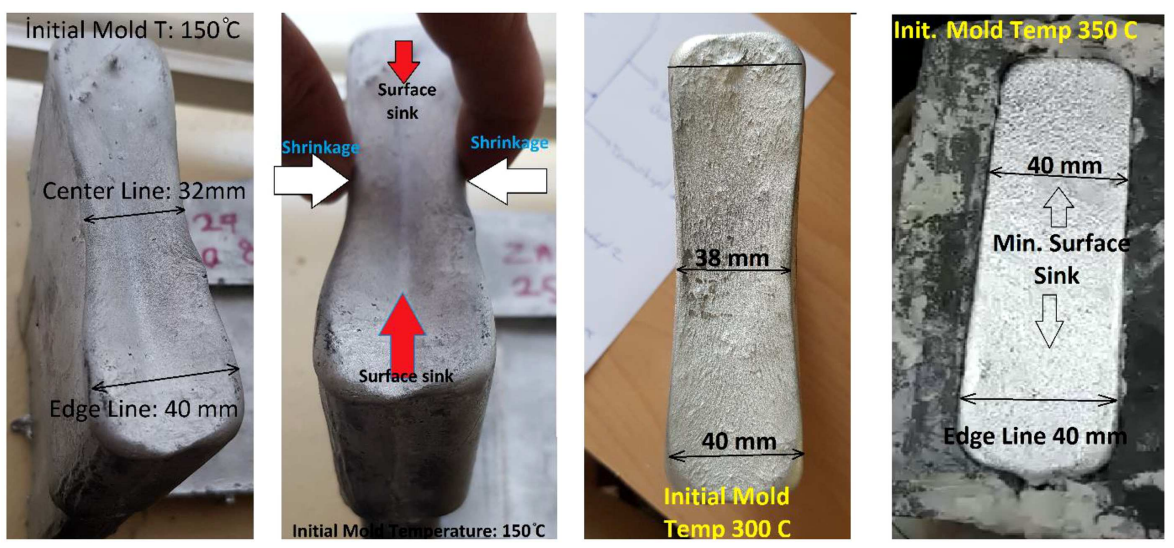

Figure 9. Shrinkage formation on upper surfaces of ZA-27 alloy after casting at different mold preheating temperatures.

uid metal filled into the mold, surface cavities generally appear on the upper surfaces. The difference between the final porosity types given in Figure 8 depends on the cooling rate. The cooling rate depends on the initial mold temperature. The shrinkage and sink $(7-8 \%)$ in the mold heated to $150^{\circ} \mathrm{C}$ are narrowed in the direction of $X$ and $Y$ axes. The shrinkage (3-6\%) of the cast, which was heated to $300^{\circ} \mathrm{C}$, expanded to the surface and became a blunt cone. Such surface shrinkages are slightly visible in the macroscopic examination. The macroscopic examination of experimentally cast ZA-27 alloy poured at the different initial mold temperatures is given in Figure 9.

The shape differences for these porosities can be justified by the phase transformations and the CLF due to the change in cooling rates. According to Akhter and Islam, the solidification of ZA-27 alloy begins with phase $\alpha^{\prime}$ dendrites and, then, with the peritectic reaction of the $\mathrm{Zn}-\beta$ rich phases around the edge of the $\alpha^{\prime}$ phase. Increase in the cooling rate decreases the peritectic reaction by increasing the solid Zn crystals in the liquid phase. Rapid cooling leads to the formation of some irregular particles such as $\alpha$ and $\eta$ during the phase $\beta$ transformation at the eutectoid temperature [39]. Peter et al. studied phase transformations and dendritic microstructural segregation of the eutectoid ZnAl22 alloy at different cooling rates. They found that an increase in the cooling rate during casting could determine the enhancement of the ratio of the eutectic transformation energy to the total melting energy and to the solidification energy, respectively. Their study illustrated that the solidification of the alloy examined was visible in the non-equilibrium condition. The separation of $\mathrm{Al}$ at the level of dendrites and the presence of eutectic transformation were expressed. The most important effect of dendritic separation was reported on the variation in the ratio of different phases. In general, it is found that different eutectoid transformations take place at different cooling rates, hence the formation of a different microstructure. Therefore, it is possible that the amount of critical fluid in the microstructure may vary as a result of off-balance solidification, which leads to a different solid-liquid interface [40]. Therefore, at high cooling rates, due to rapid solidification, shrinkage is trapped in the casting and at slow cooling rates, the porosity is shifted towards the mold top region. The ZA-27 alloy has a wide solidification range $\left(110^{\circ} \mathrm{C}\right)$ [41]; while cooling continues in this range, the liquid requirement for the perturbation of the solidified dendrites can be compensated by the flow of the interdendritic fluid. The growth of dendrite in the liquid continues to a certain fraction in the solidification range. Interdendritic liquid metal flow is not possible after this critical fraction level. In casting and foundry terminology, the blocking of liquid metal between dendrites is defined as "critical liquid fraction" [10]. In the critical fraction of the solid/liquid phase, liquid feeding is still necessary, but the solidified liquid creates a pressure decline and resistance to the liquid flow increases. If this negative pressure in the solid dendrite-liquid region cannot be compensated for by the flow of liquid due to blockage of the dendrite arms, it may lead to shrinkage and porosity [42]. In order to better investigate the effect of CLF on the surface porosity of ZA-27 alloy, a specific $1 / 2$ feeder and rectangular prism mold design was performed. Then, CLF values were selected as 40, 50, and 60 and simulation studies were performed. According to the simulation results, surface shrinkage geometry and total shrinkage percentage exhibited a significant difference. The total porosity of CLF 60 was $97.9 \%$ and it formed a deep cavity into the casting piece. The total porosity of CLF 50 and CLF 40 was $96.9 \%$ and $96 \%$, respectively, with the porosity forming a shallow and wide cavity towards the surface of the casting piece. It is known that in order to obtain sound casting, the porosity must be within the feeder volume and the total porosity must be minimum. Therefore, in this design, if the CLF is less than $40 \%$ or the feeder volume is 
larger, the porosity will be completely shifted out of the casting part. Furthermore, the CLF value affects not only macro surface porosity but also interdendritic microporosity. Macro porosity defects or surface sink are detected by visual inspection, while micro-shrinkage defects are detected by machining or RT. Microporosity defects are particularly observed during solidification of alloys with a wide solidification range, such as ZA27. With an equation developed by Niyama et al., micro-shrinkage errors can be predicted. The Niyama criterion is expressed by the formula $G / \sqrt{ } R$. $G$ and $R$ in this formula indicate the temperature gradient and the cooling rate, respectively. The Niyama Criterion can be calculated as a function of the alloy composition and below a certain threshold indicates that micro porosity may occur in that area [43]. Micro porosity is predominantly important for machine parts that require high strength and equipment subjected to high pressure. This is the reason why possible micro porosity formation criteria and their location in the ZA27 alloy were investigated. In this cast, the distribution of micro porosity in the ZA-27 alloy poured into molds at 3 different mold preheating temperatures was examined, similar to the simulations described above. The simulation results given in Figure 10 were achieved based on the Niyama criterion and were applied to determine possible microporosity locations.

In the ZA-27 alloy poured into graphite molds preheated to $150^{\circ} \mathrm{C}, 250^{\circ} \mathrm{C}$, and $350^{\circ} \mathrm{C}$, it was found that the micro porosity shifted towards the feeder region as the mold preheat temperature increased, whereas it was mostly detected in the central part of the casting part at the preheated mold temperature of $150^{\circ} \mathrm{C}$. It can be stated that with the increase in the pre-heating temperature of the mold, a casting with less risk compared to the Niyama criterion was realized. As a matter of fact, volumetric porosity defects accumulating in a certain region can decrease the strength values and cause sudden damage. The Niyama criteria observed

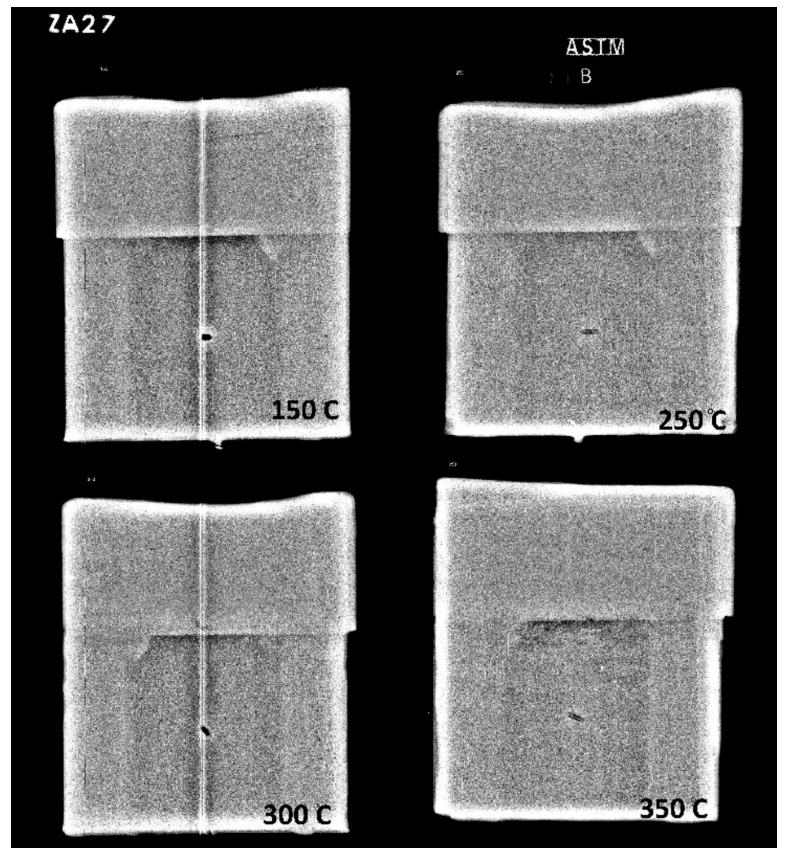

Figure 11. Radiographic test of ZA-27 castings poured at different mold preheating temperatures.

according to the simulation results were detected by Static Radiographic testing. According to the results of the radiographic examination, it was understood that no cracks or micro porosities were clearly seen in the castings made to the graphite mold heated to different temperatures. This situation is seen in the radiographic photographs in Figure 11. The applied voltage for radiography was increased from $165 \mathrm{kV}$ to $265 \mathrm{kV}$; no micro porosity was found even in this range. As a result of the experimental studies and simulation studies, it is understood that the mold preheating temperature has greater effect on the surface shrinkage and feeder hotspot rather than the microporosity, cooling rate, and Niyama. This is clearly evident from the surface sink and feeder shrinkage occurring in the feeder parts

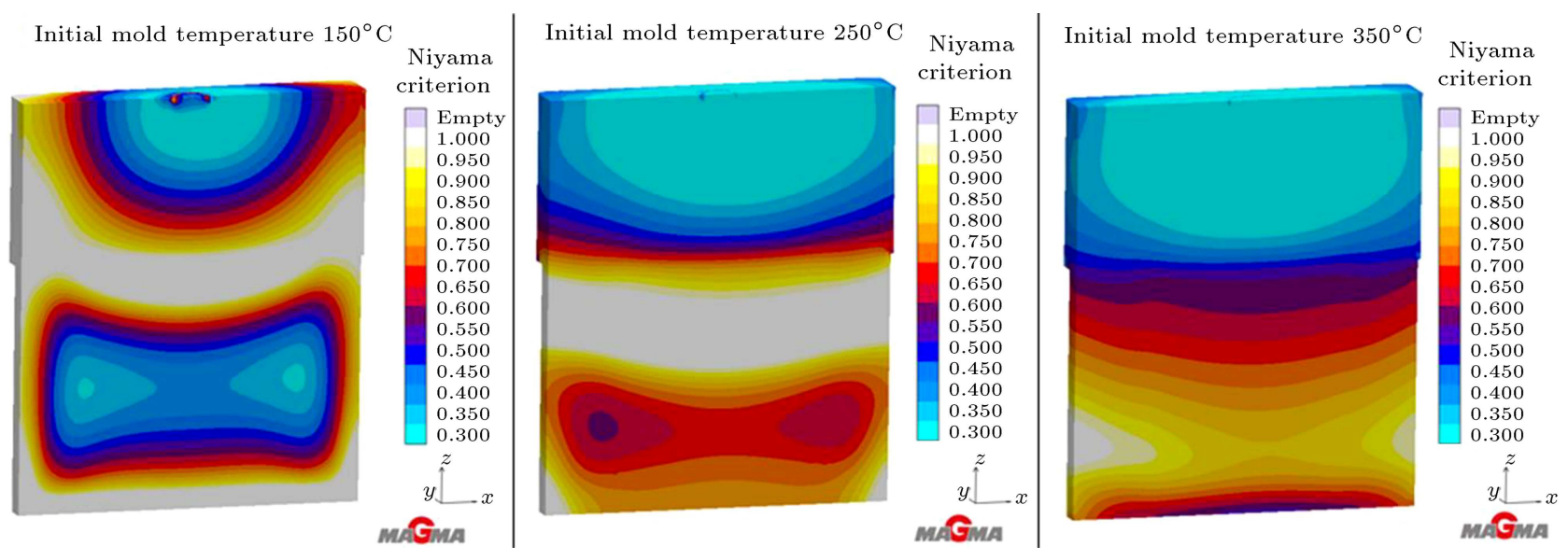

Figure 10. Niyama criterion of ZA-27 castings poured at different mold preheating temperatures. 
of the experimentally poured samples, both in the lateral and vertical directions. It is understood that the shrinkage occurring in the feeder is higher at low mold temperatures $\left(150^{\circ} \mathrm{C}-250^{\circ} \mathrm{C}\right)$ and decreases at higher mold temperatures $\left(300^{\circ} \mathrm{C}-350^{\circ} \mathrm{C}\right)$. In addition, a different feeding behavior was found when a preheating gradient was used in the mold. The lower parts of the mold were heated to $150^{\circ} \mathrm{C}$ and the upper feeder part to $350^{\circ} \mathrm{C}$. As a result of this experiment, a result similar to the feeding behavior of the mold preheated to $300^{\circ} \mathrm{C}$ was obtained.

Using the experimental data obtained from preheating, ANN algorithms were employed to predict the feeding behavior and \%shrinkage of the ZA-27 alloy. The \%shrinkage, which is calculated by ANN prediction method, is a very important parameter for foundry engineering and casting design. When the metal poured into the mold, the metal heat is lost through radiation, convection, and conduction. Following the filling of the liquid metal with the mold, heat transfer from the liquid metal to the mold surfaces occurs, followed by nucleation, grain growth, and phase transformations with heat drop. The data obtained from the experimental studies were compared with the simulations using Novacast and Magmasoft simulation software. After this study, simulation results were modified to provide high similarity with the experimental data. After this process, the second derivatives of the cooling curves obtained in the experimental study were calculated and, thus, the cooling rate and transformation temperatures were determined. As a result of experimental studies, cooling rate, cooling curve, phase transformations, liquid phase, and shrinkage data $\%$ were determined. The data obtained during the solidification is very important for understanding the metallurgical and mechanical properties of the cast ZA27 alloy. The cooling rate is related to the nucleation of the casting material and subsequent morphology of the grain structure and directly affects the mechanical properties. At high cooling rates, a fine-grained structure is formed, thus increasing mechanical strengths such as tensile and yield strengths. After cooling the ZA-27 zinc alloy from the melt to room temperature, the subsequent phase transformations $(\alpha+L), \beta,(\alpha+$ $\beta)$, and $(\alpha+\eta)$ are formed. By alloying a small amount of $\mathrm{Cu}$ to the ZA-27 alloy, an intermetallic compound $\mathrm{CuZn}_{4}$ forms through a triple eutectic reaction $(L \rightarrow$ $\alpha+\eta+\varepsilon)$ at $377^{\circ} \mathrm{C}$. At temperatures below $268^{\circ} \mathrm{C},(\varepsilon+$ $\left.\alpha \rightarrow T^{\prime}+\eta\right)$, transformation takes place and the ternary phase known as $\mathrm{Al}_{4} \mathrm{Cu}_{3} \mathrm{Zn}$ is formed. These phases formed during cooling have different lattice structures and different densities and they affect porosity and \%shrinkage. Peter et al. discussed and examined all qualitative and quantitative investigations of $\mathrm{Zn}-\mathrm{Al}$ eutectoid alloy $(22 \% \mathrm{Al})$ structures in equilibrium and non-equilibrium states and in this composition. They revealed that dendritic separation determined eutectic transformation. They found that the conditions causing phase separation during eutectic and eutectoid transformation would determine the structural modifications of the alloy when the Al segregation occurred at the dendrite level. In addition, using thermal analysis, they found that the phase transformation temperatures and microstructure could undergo changes due to different cooling rates [40]. The cooling rate of the molten zinc is determined by the balance of thermal energy released from melt to mold wall [44].

In the next experiment and learning study, data processing was performed through ANN and Mean Square Error (MSE) and, then, EPOCH diagrams were produced. Five data sets were used as inputs including initial mold temperature, solidification time, temperature-time gradient, cooling rate, and liquid phase. MSE gives the user the difference between observation and simulation. The lower the MSE value, the better the approach between observation and experiment. The stabilization of MSE is the ideal result; and if it is unstable and scattering, it means that the ANN has difficulty finding the most suitable solution and that the configuration is not ideal.

The training results using sigmoid and tangent activation functions are given in Figures 12 and 13 .

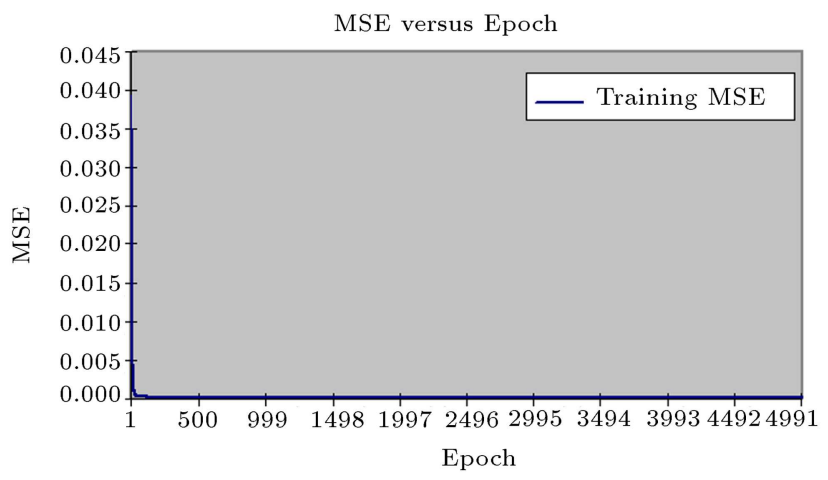

Figure 12. The MSE (Mean Square Error) and epoch diagram using Sigmoidaxon function.

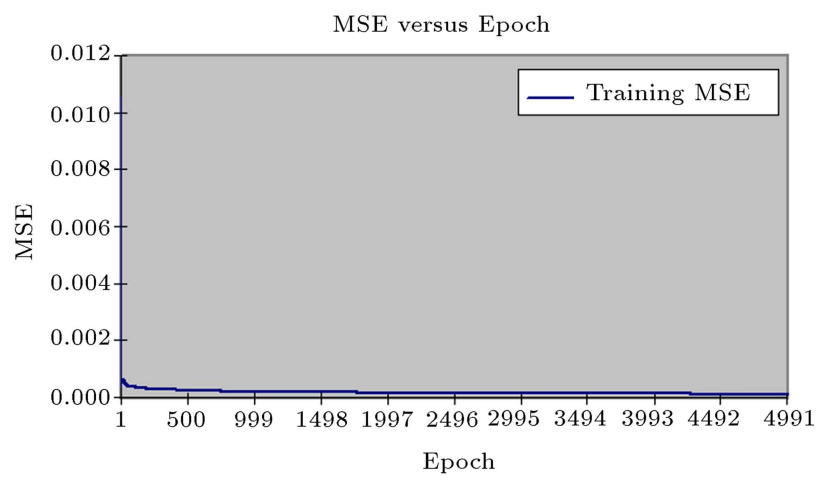

Figure 13. The MSE (Mean Square Error) and epoch diagram using Tanhaxon function. 
Following all of the conducted simulation tests, the shrinkage (output data) values were obtained through both sigmoaxon and tanhaxon training functions. The simulation results of sigmoid and tangent functions were compared with real values and each other. The results of this investigation using tangent and sigmoid activation functions illustrate that the feed forward MLP neural network consists of four layers: input, hidden 1 , hidden 2 , and output layers composed of 14 nodes in the 1 st hidden and 7 nodes in the 2nd hidden, thus producing the best results. The output data for sigmoid and tangent functions were compared with the real (experimental) data, with the results given in Figure 14. The original parameters given in Figure 14 point to the shrinkage percentage of the ZA-27 alloy obtained after experimental casting in the laboratory. The dashed (red) and dasheddotted (gray) lines, similar to the original shrinkage curve, show the modeling curves of the tanhaxon and sigmoidaxon functions, respectively. The long (black) dashed line is the temperature curve on the $Y$-axis given on the left. The data obtained in this curve were collected from thermocouples placed in the mold. This curve is typically known as the solidification or cooling curve. It is an extremely useful method for detecting both critical liquid phase ratio and phase transformations. The time expression given on the $X$ axis refers to the time elapsed after casting into the mold. In the graphic given in Figure 14, the initial mold temperature is set at $200^{\circ} \mathrm{C}$ degrees. Cooling

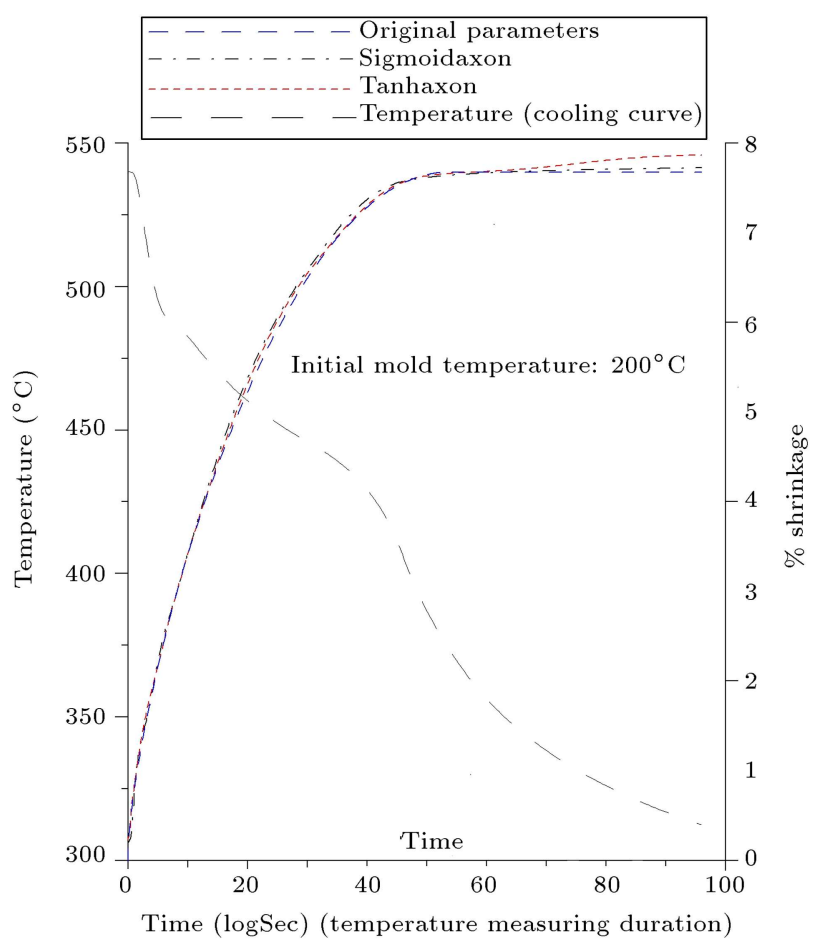

Figure 14. The \%shrinkage comparison of sigmoidaxon, tanhaxon function, and experimental data. rate data are calculated by taking the second derivative of the cooling curves obtained as a function of time. Between the outputs and targets, the correlation coefficient, $R^{2}$, makes an evaluation of how well the variation in the output is explained by the targets and outputs. In the estimation of shrinkage percentage, the determination coefficient $\left(R^{2}\right)$ was measured at $R^{2}=$ 0.9985827797 , which indicates a good match between the experimental and predicted data. Mean Absolute Deviation (MAD) is used for assessing the efficiency in process analysis. In this study, the MAD value was found to be 3.594500918 .

Upon the comparison of the experimental studies and simulation results in Figure 14, it is seen that the curves produced by both sigmoidaxon function and tanhaxon function are very close to the experimental data. After the reduction of the mold temperature to $150^{\circ} \mathrm{C}$, there was a difference between sigmoidaxon function and tanhaxon function. This may be due to the derivatives of the tanhaxon function. However, as a result of the procedure performed with sigmoidaxon function, the experimental data were obtained perfectly and the porosity rates were estimated. The \%shrinkage ratio of ZA-27 alloy, with a wide solidification range, was measured at $7.65 \%$ which was formed due to phase transformation and interdendritic spaces.

\section{Conclusions}

This study poured ZA-27 alloy into a graphite mold preheated to different temperatures, investigated metallurgical properties, and applied an Artificial Neural Network (ANN) algorithm to predict the \%shrinkage in ZA-27 casting alloy. The results obtained are listed below. The highest rate of surface sink and shrinkage was observed on the upper and lateral surfaces of the feeder at the mold preheating temperature of $150^{\circ} \mathrm{C}$. The lowest amount of shrinkage occurred in the graphite mold preheated to $350^{\circ} \mathrm{C}$. The shrinkage in the mold heated to $150^{\circ} \mathrm{C}$ is in the form of a pointed funnel elongated in the direction of gravity. The shrinkage of the cast, which was heated to $300^{\circ} \mathrm{C}$, moved to the top surface and became a blunt cone in the feeder.

It was determined that the most efficient feeding was at $350^{\circ} \mathrm{C}$ preheating and according to the Niyama criteria, the lowest porosity occurred at high mold temperatures. In molds preheated to $150^{\circ} \mathrm{C}$ and $250^{\circ} \mathrm{C}$, it was measured that during solidification, air gap was formed between the feeder and the graphite mold and the heat transfer decreased to $20 \mathrm{~W} /\left(\mathrm{m}^{2} \mathrm{~K}\right)$. The optimum heat transfer coefficient $(\mathrm{h})$ between ZA-27 alloy and graphite mold was found at $2000 \mathrm{~W} /\left(\mathrm{m}^{2} \mathrm{~K}\right)$. The most effective feeder efficiency was detected in the mold preheated to $350^{\circ} \mathrm{C}$ and no microporosity was detected according to the radiography results.

ANN architecture was designed as in the following 
arrangement (5-14-7-1): 5 inputs, 1 output, 14 hidden layers (1 neuron), and 7 hidden layers (2 neurons). In addition, the network model operated by Genetic Algorithms (GA) was used in the training data. Two different functions called sigmoid (sigmoaxon) and tangent (tanhaxon) were used for training the model. Momentum Learning Rule and Online Weight Update were employed for each function. Optimum ANNs were designed, trained, and tested to predict shrinkage rate at various initial mold temperatures and in physical conditions. Good results were obtained in both functions. Thanks to the sigmoid (sigmoaxon) function training, the most systematic modeling ANN set was revealed with $99 \%$ (Vol. $7.65 \%$ shrinkage) prediction.

An ANN model along with sigmoidaxon and tanhaxon function with one input, two hidden and one output layers was applied to the prediction of \%shrinkage. The calculations using the obtained models are in good agreement with experimental data. The ANN model is a very useful tool to identify the shrinkage parameters which are significant for the metal cast materials and they can be used as practical tools in production control in metal casting foundries.

\section{Acknowledgments}

The author would like to express thanks to Mr. Soner Özden Ertürk and Murat Akçin for their contribution.

\section{Nomenclature}

$\begin{array}{ll}\text { ZA } & \text { Zinc-Aluminum } \\ \text { ANN } & \text { Artificial Neural Network } \\ \text { CAS } & \text { Computer-Aided Simulation } \\ \text { RT } & \text { Radiographic inspection } \\ \text { SiC } & \text { Silicon Carbide } \\ \text { HTC } & \text { Heat Transfer Coefficient } \\ \text { GA } & \text { Genetic Algorithm } \\ \text { PSO } & \text { Particle Swarm Optimization } \\ \text { ReLU } & \text { Rectified Linear activation function } \\ \text { PReLU } & \text { Parametric Rectified Linear Unit } \\ \text { EDM } & \text { Electrical Discharge Machining } \\ \text { BPNN } & \text { Back Propagation Neural Network } \\ \text { FFNN } & \text { Feed-Forward Neural Network } \\ \text { CLF } & \text { Critical Liquid Fraction } \\ \text { BPA } & \text { Back Propagation Algorithms } \\ \text { MSE } & \text { Mean Square Error } \\ \text { MAD } & \text { Mean Absolute Deviation }\end{array}$

\section{References}

1. David, R., Shrivastava, V., Dasgupta, R., Prasad, B.K., and Singh, I.B. "Corrosion investigation of zincaluminum alloy (ZA-27) matrix reinforced with in situ synthesized titanium carbide particle composites", $J$. Mater. Eng. Perform., 28(4), pp. 2356-2364 (2019).

2. Genel, K., Kurnaz, S.C., and Durman, M. "Modeling of tribological properties of alumina fiber reinforced zinc-aluminum composites using artificial neural network", Mater. Sci. Eng. A, 363(1), pp. 203-210 (2003).

3. Pola, A., Tocci, M., and Goodwin, F.E. "Review of microstructures and properties of zinc alloys", Metals, 10(2), p. 253 (2020).

4. Pürçek, G. "Improvement of mechanical properties for $\mathrm{Zn}-\mathrm{Al}$ alloys using equal-channel angular pressing", $J$. Mater. Process. Technol., 169(2), pp. 242-248 (2005).

5. Santos, G.A., de Moura Neto, C., Osório, W.R., and Garcia, A. "Design of mechanical properties of a Zn27Al alloy based on microstructure dendritic array spacing", Mater. Des., 28(9), pp. 2425-2430 (2007).

6. Movahedi, N., Murch, G.E., Belova, I.V., and Fiedler, T. "Effect of heat treatment on the compressive behavior of zinc alloy ZA27 syntactic foam", Materials, 12(5), p. 792 (2019).

7. Nilsson, A., Gabrielson, P., and Ståhl, J.-E. "Zincalloys as tool materials in short-run sheet-metal forming processes: Experimental analysis of three different zinc-alloys", J. Mater. Process. Technol., 125-126, pp. 806-813 (2002).

8. Zhang, Z.M., Wang, J.C., Liu, H.Z., and Guo, X.F. "Effect of annealing on damping capacities of as-cast ZA27 alloy", Acta Metall. Sin. Engl. Lett., 19(5), pp. 379-384 (2006).

9. Chen, T.J., Hao, Y., Sun, J., and Li, Y.D. "Effects of processing parameters on tensile properties and hardness of thixoformed ZA27 alloy", Mater. Sci. Eng. A, 382(1), pp. 90-103 (2004).

10. Kumruoglu, L.C. and Özer, A. "Investigation of critical liquid fraction factor in nodular iron castings by computer simulation", J. Mater. Process. Technol., 197(1), pp. 182-188 (2008).

11. Savaşkan, T. and Aydıner, A. "Effects of silicon content on the mechanical and tribological properties of monotectoid-based zinc-aluminium-silicon alloys", Wear, 257(3), pp. 377-388 (2004).

12. Zhao, P., Zhang, J., Dong, Z., Huang, J., Zhou, H., $\mathrm{Fu}$, J., and Turng, L.-S. "Intelligent injection molding on sensing, optimization, and control", Advances in Polymer Technology, 2020, Article ID 7023616, 22 pages (2020).

https:// www.hindawi.com/journals/apt/2020 /7023616/

13. Yang, L.J. "The effect of solidification time in squeeze casting of aluminium and zinc alloys", J. Mater. Process. Technol., 192-193, pp. 114-120 (2007).

14. Zhao, P., Dong, Z., Zhang, J., Zhang, Y., Cao, M., Zhu, Z., Zhou, H., and Fu, J. "Optimization of injection-molding process parameters for weight control: converting optimization 
problem to classification problem", Advances in Polymer Technology, 2020, Article ID 7654249, 9 pages (2020). https://www.hindawi.com/journals /apt/2020/7654249/

15. Cao, L., Liao, D., Sun, F., Chen, T., Teng, Z., and Tang, Y. "Prediction of gas entrapment defects during zinc alloy high-pressure die casting based on gas-liquid multiphase flow model", Int. J. Adv. Manuf. Technol., 94(1), pp. 807-815 (2018).

16. Shafyei, A., Anijdan, S.H.M., and Bahrami, A. "Prediction of porosity percent in $\mathrm{Al}-\mathrm{Si}$ casting alloys using ANN", Mater. Sci. Eng. A, 431(1), pp. 206-210 (2006).

17. Aravind, S., Ragupathi, P., and Vignesh, G. "Numerical and experimental approach to eliminate defects in al alloy pump- crank case processed through gravity die casting route", Mater. Today Proc. (2020).

18. Haykin, S., Neural Networks, a Comprehensive Foundation, Prentice HallUpper Saddle River; New Jersey 07458, pp. 157-173 (1999).

19. Abiodun, O.I., Jantan, A., Omolara, A.E., Dada, K.V., Mohamed, N.A., and Arshad, H. "State-of-theart in artificial neural network applications: A survey", Heliyon, 4(11), p. e00938 (2018).

20. Moslehi, F., Haeri, A., and Martínez-Álvarez, F. "A novel hybrid GA-PSO framework for mining quantitative association rules", Soft Comput., 24(6), pp. 46454666 (2020).

21. Mohamed, Z.E. "Using the artificial neural networks for prediction and validating solar radiation", J. Egypt. Math. Soc., 27(1), p. 47 (2019).

22. Sharma, S. "Activation functions in neural networks", https://towardsdatascience.com/activationfunctionsneural-networks-1cbd9f8d91d6, 08/2021.

23. Cavaleri, L., Asteris, P.G., Psyllaki, P.P., Douvika, M.G., Skentou, A.D., and Vaxevanidis, N.M. "Prediction of surface treatment effects on the tribological performance of tool steels using artificial neural networks", Appl. Sci., 9(14), p. 2788 (2019).

24. Guo, Z. and Sha, W. "Modelling the correlation between processing parameters and properties of maraging steels using artificial neural network", Comput. Mater. Sci., 29(1), pp. 12-28 (2004).

25. (Tony) Hou, T.-H., Su, C.-H., and Chang, H.-Z. "Using neural networks and immune algorithms to find the optimal parameters for an IC wire bonding process", Expert Syst. Appl., 34(1), pp. 427-436 (2008).

26. Ibrahim, D. "An overview of soft computing", Procedia Comput. Sci., 102, pp. 34-38 (2016).

27. Azadi Moghaddam, M. and Kolahan, F. "Modeling and optimization of the electrical discharge machining process based on a combined artificial neural network and particle swarm optimization algorithm", Sci. Iran., 27(3), pp. 1206-1217 (2019).

28. Altabey, W.A., Noori, M., Alarjani, A., and Zhao, Y. "Tensile creep monitoring of basalt ber-reinforced polymer plates via electrical potential change and artificial neural network", Sci. Iran., Transactions B: Mechanical Engineering, 27(4), pp. 1995-2008 (2020).

29. Manikandan, S.G.K., Sivakumar, D., and Kamaraj, M. "1-Physical metallurgy of alloy 718", In Welding the Inconel 718 Superalloy, S.G.K. Manikandan, D. Sivakumar, and M. Kamaraj, Eds., Elsevier, pp. 1-19 (January 1, 2019).

30. Hou, W., Zhang, D., Wei, Y., Guo, J., and Zhang, X. "Review on computer aided weld defect detection from radiography images", Appl. Sci., 10(5), p. 1878 (2020).

31. Mohd Hashim, S.A. "The use of ANN to automate welding defect detection-a review", Jurnal Ilka Bil. 1, Kolokium Penyelidikan Dan Bengkel Penulisan Jurnal Ilka Zon Utara, pp. 31-43 (2015).

32. Guler, M.O. and Artir, R. "Modular neural network modeling of compressive strength of high-alumina bricks by using tangent function", Mater. Des., 28(1), pp. 112-118 (2007).

33. Yang, H., Jia, B., Zhang, Z., Qu, X., Li, G., Lin, W., Zhu, D., Dai, K., and Zheng, Y. "Alloying design of biodegradable zinc as promising bone implants for load-bearing applications", Nat. Commun., 11(1), p. 401 (2020).

34. MES-Die-Casting-Design-Guide.pdf (n.d.).

35. Li, W. and Cui, J. "A new method for quickly locating the hot spots in solidification simulation of complicated castings", Int. J. Cast Met. Res., 15(4), pp. 319-323 (2003).

36. Wankhede, D.M., Narkhede, B.E., Mahajan, S.K., and Choudhari, C.M. "Influence of pouring temperature and external chills on mechanical properties of aluminum silicon alloy castings", Mater. Today Proc., 5(9, Part 3), pp. 17627-17635 (2018).

37. Anerao, P.R. and Munde, Y.S. "Thermal analysis of feeder neck using FEM for a metal casting", Int. J. Emerg. Technol. Adv. Eng., 2(8), pp. 104-108 (2012). (ISSN 2250-2459)

38. Khalajzadeh, V. and Beckermann, C. "Simulation of shrinkage porosity formation during alloy solidification", Metall. Mater. Trans. A, 51(5), pp. 2239-2254 (2020).

39. Akhter, R. and Islam, R. "Effect of mould preheat temperature on the solidification structures of $\mathrm{Zn}$ 27Al Alloy", International Journal of Engineering and Technical Research (IJETR), 5(2), p. 4 (2016).

40. Peter, I., Agapie, M., and Varga, B. "Dendritic segregation of Zn-Al eutectoid alloys", Metals, 8(11), p. 924 (2018).

41. Li, M., Li, Y., Zhou, H., Li, M., Li, Y., and Zhou, H. "Microstructure and mechanical properties of ZA27 alloy rheo-diecasting process fabricated by self-inoculation method", Mater. Res., 23(4) (2020). https://doi.org/10.1590/1980-5373-MR-2020-0101

42. Kayikci, R., Çolak, M., Sirin, S., and Kocaman, E. "Determination of the critical fraction of solid during the solidification of a PM-cast aluminium alloy", Mater. Tehnol., 49(5), pp. 797-800 (2015). 
43. Tavakoli, R. and Davami, P. "Automatic optimal feeder design in steel casting process", Comput. Methods Appl. Mech. Eng., 197(9), pp. 921-932 (2008).

44. Fuwa, D., Sakuragi, T., Mizubayashi, M., Kobayashi, M., and Katsumi, T. "Prediction of laminations in zinc alloy die-casting by gas-liquid two-phase flow simulation", Mater. Trans., 60(5), pp. 793-801 (2019).

\section{Biography}

Levent Cenk Kumrouğlu is an Associate Professor at İskenderun Technical University Faculty of Engineering and Natural Sciences. Previous academic tasks include (a) metallurgical and materials engineering, working as an Associate Professor at the Department of Metallurgy and Materials Engineering and (b) large plasma and surfaces at the Research Laboratory of the University of Sheffield (England), Republican State University (Turkey). He also has several years of experience in the industry. Dr. Kumruoglu has extensive expertise in Surface Engineering with its main research areas covering various aspects of plasma-assisted electrolytic, atmospheric pressure, and vacuum-based processes for surface treatment and coating of metals to ensure their sustainability and to open new processing paths for the production of metals. Also, he works on casting and casting properties of different metals such as zinc, aluminum, magnesium, and cast iron. 